\title{
Synthesis of Low-Size Flower-Like AIOOH Structures
}

\author{
Olga V. Bakina ${ }^{1,2, a)}$, Elena A. Glazkova ${ }^{1,2, b)}$, Natalia V. Svarovskaya ${ }^{1,2,3, c)}$, \\ Aleksandr S. Lozhkomoev ${ }^{1,2, \text { d) }}$, Elena G. Khorobraya ${ }^{1, \mathrm{e})}$, \\ and Sergey G. Psakhie ${ }^{1,2, \text { f) }}$ \\ ${ }^{1}$ Institute of Strength Physics and Materials Science SB RAS, Tomsk, 634055, Russia \\ ${ }^{2}$ National Research Tomsk Polytechnic University, Tomsk, 634050, Russia \\ ${ }^{3}$ National Research Tomsk State University, Tomsk, 634050, Russia \\ a) Corresponding author: ovbakina@ispms.tsc.ru \\ b) eagl@ispms.tsc.ru \\ c)nvsv@ispms.tsc.ru \\ d) asl@ispms.tsc.ru \\ e) egx@mail.ru \\ f) sp@ms.tsc.ru
}

\begin{abstract}
Al} / \mathrm{Cu}, \mathrm{Al} / \mathrm{Zn}$, and $\mathrm{Al} / \mathrm{Fe}$ bimetallic nanoparticles have been obtained using the method of simultaneous electrical explosion of metal pairs in an argon atmosphere. The nanoparticles are chemically active and interact with water at $60^{\circ} \mathrm{C}$ forming flower-like hierarchical porous structures with a high specific surface area. As the $\mathrm{Al} / \mathrm{Cu}$ nanopowder is oxidized with water, flower-like pseudoboehmite composite structures are formed with the size of under $1.0 \mu \mathrm{m}$; structurally heterogeneous electron-dense spherical inclusions of unreacted metal copper and intermetallides are identified inside them. Al/Fe product transformations are presented by the flower-like pseudoboehmite surrounded by lamellar structures enriched with ferric oxides. $\mathrm{Al} / \mathrm{Zn}$ nanoparticles react with water, forming the flower-like pseudoboehmite and mainly hexagonal zinc oxide laminae. The composite particles obtained can be used as antibacterial agents in manufacturing medical supplies.
\end{abstract}

Keywords: flower-like $\mathrm{AlOOH}$, hydrolysis, simultaneous electrical explosion of metal pairs

\section{INTRODUCTION}

Recently there has been a strong emphasis on the morphology of nanoparticles and nanomaterials, which is directly related to their properties and the fields of application [1-4]. Many studies are devoted to the research of various flower-like nanostructures of aluminum, copper, titanium, iron, tin, and zinc oxides [1-5]. Such structures exhibit a developed surface, porosity, and high catalytic and adsorption activity [6,7]. Among these structures, we can highlight aluminum oxide with a flower-like morphology, which is stable up to $900^{\circ} \mathrm{C}$ and is capable of adsorbing bacteria, viruses, DNA/RNA, proteins, endotoxins, and antigens [8]. To create novel materials, the perspective precursors are $\mathrm{Al} / \mathrm{Cu}, \mathrm{Al} / \mathrm{Zn}$, and $\mathrm{Al} / \mathrm{Fe}$ bimetallic nanoparticles. The composite particles synthesized on the basis of these bimetallic nanoparticles, in whose structure the pseudoboehmite nanopetals and nanosized particles of biometal $(\mathrm{Cu}, \mathrm{Zn}, \mathrm{Fe})$ are combined, are expected to exhibit complementary functional properties, that will considerably widen the fields of their practical application.

The present work aims to investigate the morphology and phase constitution of the composite flower-like structures obtained from the reaction of $\mathrm{Al} / \mathrm{Cu}, \mathrm{Al} / \mathrm{Zn}$, and $\mathrm{Al} / \mathrm{Fe}$ bimetallic nanoparticles with water.

\section{EXPERIMENTAL PROCEDURE}

The $\mathrm{Al} / \mathrm{Cu}, \mathrm{Al} / \mathrm{Zn}$, and $\mathrm{Al} / \mathrm{Fe}$ bimetallic particle nanopowders were obtained using the method of simultaneous electrical explosion of aluminum and copper (zinc or iron) wires in an argon atmosphere with the 50:50 ratio of

(C) 2014 AIP Publishing LLC 978-0-7354-1260-6/\$30.00 
metals. In terms of the nature of the metals used, their correlation and explosion conditions, this method enables the production of compound nanoparticles comprising several phases separated by interphase boundaries. During the electrical explosion, alloys, solid solutions, and intermetallides are formed.

The composite particles were obtained by the oxidation of nanopowders with water using the following method. $0.5 \mathrm{~g}$ of nanopowder were placed into a heat-insulated reaction vessel, then $50 \mathrm{ml}$ of distilled water were added, and the mixture was heated to $60^{\circ} \mathrm{C}$, being continuously stirred. The reaction was performed for 60 min; the obtained products were washed, filtered, and dried to a constant mass.

The morphology and size of the bimetallic nanoparticles and composite particles were determined by transmission electron microscopy (JEM-2000FX JEOL, Japan). The iron-bearing objects were studied using High Resolution SEM (Zeiss Ultra-Plus FEG-SEM, Germany). The phase constitution was determined by X-ray diffraction analysis using $\mathrm{CuK}_{\alpha}$-radiation, $\lambda=1.54056 \AA$ (XRD-6000, Shimadzu, Japan). The phases were identified using the PCPDFWIN software. The texture characteristics were determined by the method of low-temperature nitrogen adsorption (Sorbtometer-M, Russia), the specific surface area was calculated with the 5-point BET method.

\section{DISCUSSION OF RESULTS}

\section{Precursor Nanoparticles}

Under the same parameters of the electrical explosion of aluminum and copper (zinc or iron) wires, spherical particles are formed, whose average size is $80-120 \mathrm{~nm}$ and the particle size does not depend on the pattern composition (Fig. 1). The surface of the particles is covered with a thin inhibitive oxide film. The specific surface area of the patterns is $6-8 \mathrm{~m}^{2} / \mathrm{g}$.

The study of the morphology and elemental composition of $\mathrm{Al} / \mathrm{Cu}$ nanoparticles using the EDAX-TEM method showed that all analyzed particles contain $\mathrm{Al}$ and $\mathrm{Cu}$ in different portions, which are uniformly distributed over the particles. The particles contains $5 \%$ (mass fraction) of $\mathrm{Al}_{2} \mathrm{O}_{3}$ (Fig. 1(a)). The major reflexes correspond to the $\mathrm{Cu}_{2} \mathrm{Al}$ intermetallic compound in the diffraction patterns of all nanopowders. There are also phases of $\mathrm{Al}, \mathrm{Cu}$ metals and $\mathrm{Cu}_{4} \mathrm{Al}$ and $\mathrm{Al}_{9} \mathrm{Cu}$ intermetallides in the patterns, that corresponds to the $\mathrm{Cu}-\mathrm{Al}$ system state diagram. The comparison of the data of the EDAX-TEM and RPA analyses allows us to suggest that the particles have a complex inner structure and consist of clusters of different phase constitutions.

Under electrical explosion $(T \sim 10000 \mathrm{~K})$, aluminum and iron can form intermetallic compounds, solid solutions and eutectics. In the diffraction pattern of $\mathrm{Al} / \mathrm{Fe}$ nanoparticles, the major reflexes correspond to the intermetallic compound-iron monoaluminide $\mathrm{FeAl}$ (73\%) (Fig. 1(b)). Besides, there are phases of solid solution $\mathrm{Fe}_{2} \mathrm{Al}(16 \%)$ and metallic $\mathrm{Al}(11 \%)$, that corresponds to the $\mathrm{Fe}-\mathrm{Al}$ system state diagram [9]. The phase constitution of $\mathrm{Al} / \mathrm{Zn}$ nanoparticles is presented by the $\mathrm{Al}$ and $\mathrm{Zn}$ phases and the $\mathrm{Al}_{0.71} \mathrm{Zn}_{0.29}$ solid solution. As the elemental composition of the $\mathrm{Al} / \mathrm{Zn}$ nanoparticles is investigated using the TEM method in the mapping mode, there is a distinguished boundary of metallic phase separation (Fig. 1(c)).
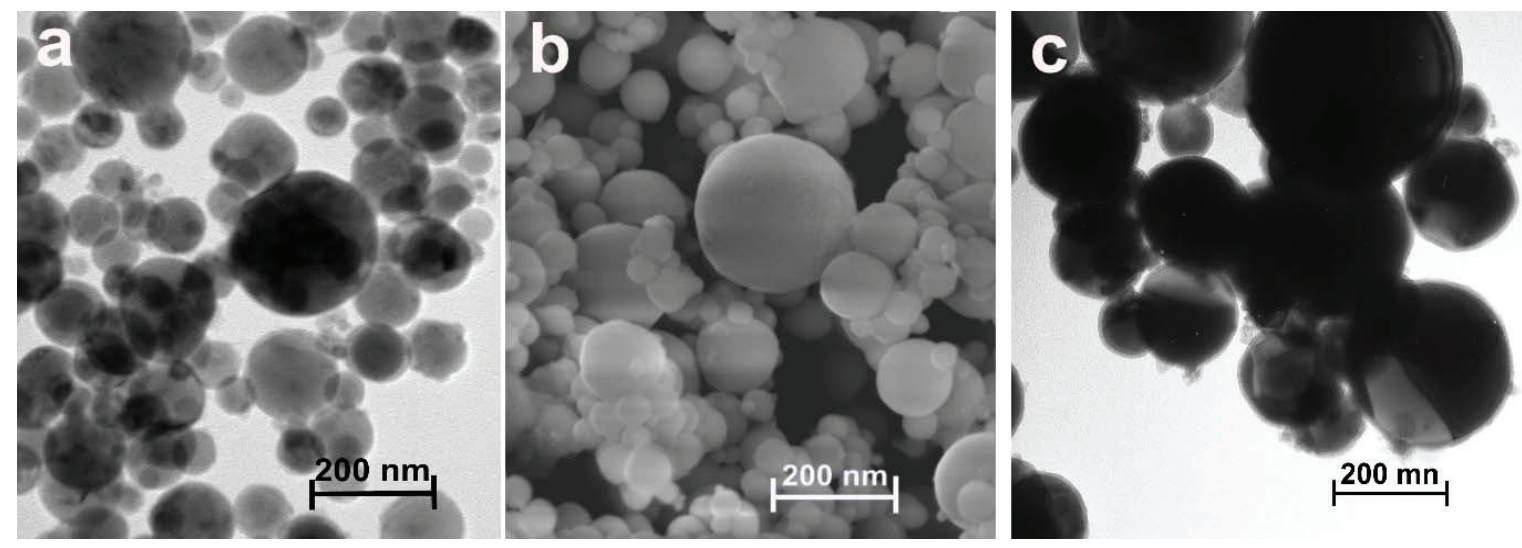

FIGURE 1. Microimages of $\mathrm{Al} / \mathrm{Cu}(\mathrm{a}), \mathrm{Al} / \mathrm{Fe}(\mathrm{b})$, and $\mathrm{Al} / \mathrm{Zn}$ (c) bimetallic nanoparticles 

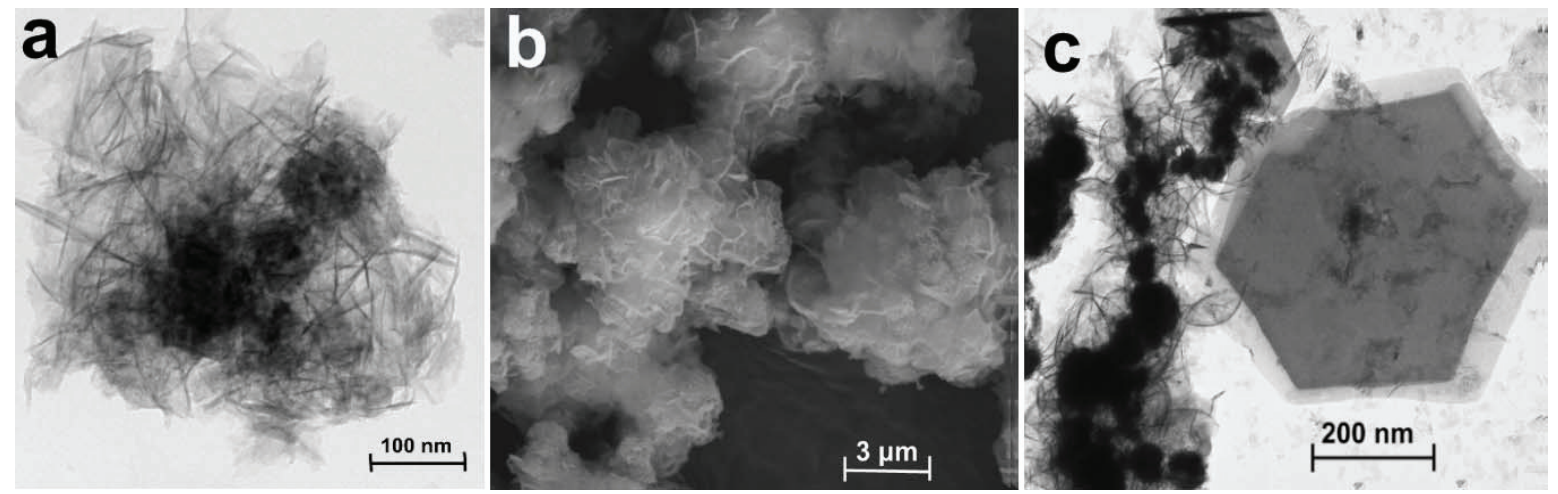

FIGURE 2. Microimages of composite particles produced during the reaction with water: (a) $\mathrm{Al} / \mathrm{Cu}$, (b) $\mathrm{Al} / \mathrm{Fe}$ and (c) $\mathrm{Al} / \mathrm{Zn}$

Bimetallic nanoparticles are represented by the electrical explosion products of $\mathrm{Al}$ and $\mathrm{Cu}, \mathrm{Al}$ and $\mathrm{Fe}$ metal pairs, while in the structure of the major amount the intermatallides of various composition are detected without an evident separation of metallic components. Under the electrical exlosion of the $\mathrm{Al}$ and $\mathrm{Zn}$ metal pair, intermetallides are not formed, and the metallic phases have interfaces in the structure of the $\mathrm{Al} / \mathrm{Zn}$ nanoparticles.

\section{Flower-Like Structures}

The bimetallic nanoparticles studied under the conditions of the experiment are chemically active and interact with water at $60^{\circ} \mathrm{C}$ as well as metallic aluminum electroexplosive nanopowder [10]. The reaction is exothermal and is followed by the release of hydrogen and a change in the reaction medium's $\mathrm{pH}$. Porous structures of various morphology are formed as a result of the transformation of bimetallic nanopowders.

The composite particles obtained after $\mathrm{Al} / \mathrm{Cu}$ oxidation present the pseudoboehmite nanopetals agglomerates with heterogeneous electron-dense spherical inclusions (Fig. 2(a)). In their size, the nanopetals (100-300 nm wide and 5-7 nm thick) are similar to the oxidation products under the same conditions of electroexplosive Al nanopowders (Fig. 3) [10]. The study of the substructure characteristics of agglomerates by comparing the brightfield and the dark-field TEM-images and the elemental composition of agglomerates by the energy-dispersion analysis revealed that the electron-dense inclusions are enriched with copper and consist of units sized below $10 \mathrm{~nm}$ (Fig. 2(a)). According to the X-ray phase analysis, copper and intermetallides are at the same ratios as in the initial nanopowders. The specific surface area of the copper-containing composite particles is $130 \mathrm{~m}^{2} / \mathrm{g}$.

As a result of the $\mathrm{Al} / \mathrm{Fe}$ transformation, flower-like hierarchical porous structures are formed (Fig. 2(b)), which consist of two types of lamina. The $\mathrm{Al} / \mathrm{Fe}$ nanoparticle transformation products are presented by a $0.5-1.0 \mu \mathrm{m}$ spherical porous agglomerate of pseudoboehmite nanopetals surrounded by lamellar structures enriched with ferric oxides with a specific surface area of $124 \mathrm{~m}^{2} / \mathrm{g}$.
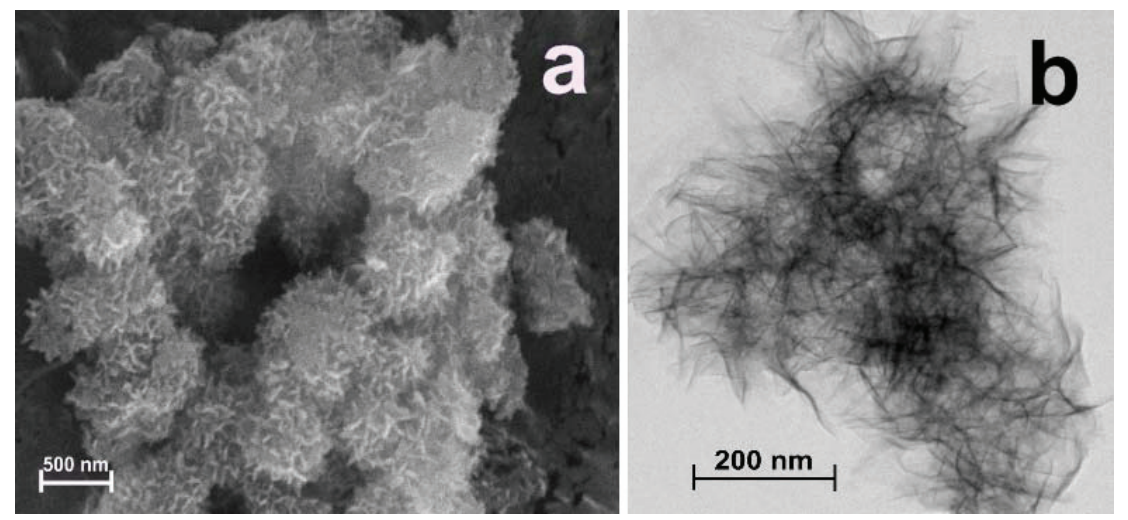

FIGURE 3. Flower-like AlOOH: (a) SEM and (b) TEM images 
According to the X-ray phase analysis, the synthesized porous structures are presented by the $\mathrm{Fe}_{3} \mathrm{O}_{4}$ phases, intermetallides, and solid solutions with a differing ratio of $\mathrm{Al}$ and $\mathrm{Fe}$, which do not react with water in the experiment.

The $\mathrm{Al} / \mathrm{Zn}$ nanoparticle transformation products are presented by a spherical flower-like agglomerate of pseudoboehmite nanopetals and zinc oxide hexagonal laminae (Fig. 2(c)). The specific surface area of the patterns is $229 \mathrm{~m}^{2} / \mathrm{g}$. The study of the phase constitution of the given composite revealed the presence of $\mathrm{Al}_{2} \mathrm{O}_{3}, \mathrm{AlOOH}$, and $\mathrm{ZnO}$ phases.

\section{CONCLUSION}

Thus, electroexplosive bimetallic particles react with water under soft conditions forming flower-like hierarchical porous structures with a high specific surface area. The shape-size characteristics of pseudoboehmite nanopetals in the structures under study are maintained, and the change in the morphology of the composite particles is caused by the phase constitution of a precursor.

\section{ACKNOWLEDGEMENTS}

The present work was financially supported by the Program of Fundamental Researches of the State Academies of Sciences for 2013-2020 and RFBR grant 14-08-31363.

The authors are grateful to K. B. Krukovsky and A. A. Miller, the researchers at CUC "NanoTech" of the Institute of Strength Physics and Materials Science of the Siberian Branch of the Russian Academy of Sciences for electron microscope investigations.

\section{REFERENCES}

1. R. Azimirad and S. Safa, Synt. React. Inorg. M 44, 798 (2014).

2. M. Y. A. Rahman, A. A. Umar, L. Roza, and M. M. Salleh, Micro Nano Lett. 9, 253 (2014).

3. R. Suresh, K. Giribabu, R. Manigandan, A. Vijayaraj, R. Prabu, A. Stephen, and V. Narayanan, J. Iran. Chem. Soc. 11, 645 (2014).

4. Q. Guo and X. Qin, J. Solid State Electr. 18, 1031 (2014).

5. P. K. Baitha, P. P. Pal, J. Manam, K. Pankaj, and P. J. Partha, Nucl. Instrum. Meth. A 745, 91 (2014).

6. Z. Y. Wu, F. J. Li, C. Li, Z. W. Zhu, and M. Fang, Chinese J. Inorg. Chem. 29, 2091 (2013).

7. X. Huang, Y. Jing, J. Yang, et al., Mater. Res. Bull. 51, 271 (2014).

8. F. Tepper, L. Kaledin, and T. Kaledin, J. Liq. Chromatogr. R 32, 607 (2009).

9. N. P. Lyakishev, State Diagrams of Double Metallic Systems (Moscow, 1996).

10. N. V. Svarovskaya, O. V. Bakina, E. A. Glazkova, M. I. Lerner, and S. G. Psakhie, Russ. J. Phys. Chem. A 84, $1566(2010)$ 